\title{
Optimal X-ray Energy for Digital Mammography
}

\author{
C. M. Logan
}

J. M. Hernandez

J. H. Kinney

D. L. Lewis

November 1992

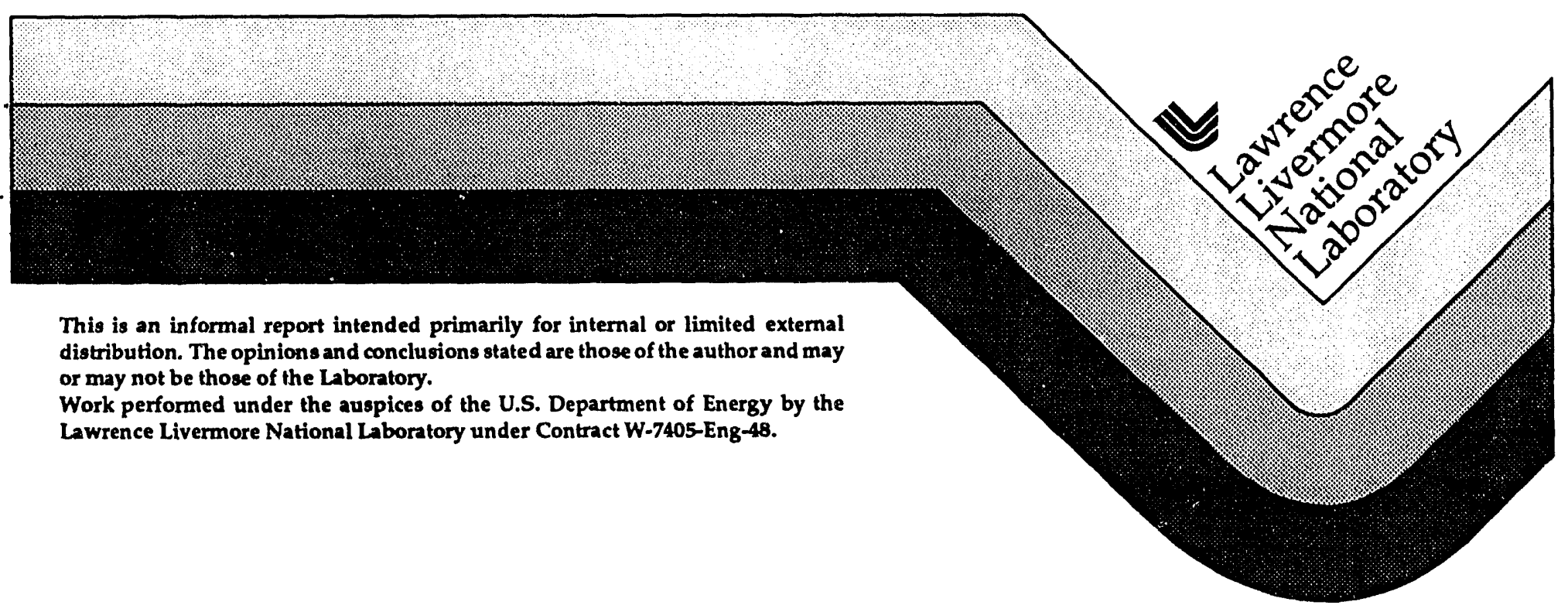




\section{DISCLAIMER}

This document was prepared as an account of work sponsored by an agency of the United States Government. Neither the United States Government nor the University of California nor any of their employees, makes any warranty, express or implied, or assumes any legal liability or responsibility for the accuracy, completeness, or usefulness of any information, apparatus, product, or process disclosed, or represents that its use would not infringe privately owned rights. Reference herein to any specific commercial products, process, or service by trade name, trademark, manufacturer, or otherwise, does not necessarily constitute or imply its endorsement, recommendation, or favoring by the United States Government or the University of California. The views and opinions of authors expressed herein do not necessarily state or reflect those of the United States Government or the University of California, and shall not be used for advertising or product endorsement purposes.

This report has been reproduced directly from the best available copy.

A vailable to DOE and DOE contractors from the Office of Scientific and Technical Information

P.O. Box 62, Oak Ridge, TN 37831

Prices available from (615) 576-8401, FTS 626.8401

Available to the public from the

National Technical Information Service

U.S. Department of Commerce

5285 Port Royal Rd.,

Springfield, VA 22161 
Abstract

Screening mammography is a radiological procedure requiring the highest possible image quality at the lowest possible dose. It is widely recognized that digital image acquisition, computer assisted diagnosis, and scientific visualization can provide substantial improvement in mammography. For such systems, much of what is accepted as best practice with today's film/screen/lightbox systems will become inappropriate. A complete system design is required. We have constructed a model of the breast imaging process. These results show that molybdenum-anode, molybdenum-filtered x-ray spectra are ill-suited for digital mammography. An $\mathrm{x}$-ray spectrum rich in 22 -to $25-\mathrm{keV}$ photons is needed.

Introduction

The mammography industry is dominated by film/screen/lightbox (FISLIB) systems using molybdenum-anode, molybdenum-filtered (Mo/Mo) $\mathrm{x}$-ray spectra. 1,2 The main reasons for this dominance are that they deliver high-contrast images when used with today's film/screen, dose is acceptable, and Mo is a robust anode material 3,4 . One undesirable attribute of these systems is that they allow very little spectral tailoring. The spectra are dominated by the Mo characteristic lines at 17.5 and $19.6 \mathrm{keV}$. In the usual practice, the only spectral adjustment that is made is slight adjustment in the electron accelerating potential $(\mathrm{kVp})$. Changes within the usual range have only minor effect on the resulting output spectra.

The compromise in system design caused by the FISLIB system is enormous. Since the human observer has poor grey-level discrimination, high overall contrast is paramount. Thus much of what is accepted best practice for today's mammography has been driven by the demand for high contrast at the point of display. The choice of the Mo/Mo x-ray spectrum and the characteristics of film, in particular, are driven by the need for high contrast in the image display and the unfortunate fact that the lightbox has no contrast control.

With a digital mammography system, contrast is a parameter to be chosen and varied at the point of image display/visualization, not an integral attribute of the entire system. In effect, one is free to perform image processing with a computer rather than by compromising system design. We present here results of modelling the breast imaging process. Implicit in our approach is that the appropriate measure of system performance is the dose required to reliably detect a specified flaw and that one will choose to terminate the exposure when sufficient photons have been counted to achieve reliable detection. This is profoundly different from a FISLIB system with which an exposure must continue until a target film density is achieved and then must be terminated whether or not the required imaging task is accomplished.

Optimizing Spectral Performance

A simple model of the breast imaging challenge is to consider the task of imaging a cubic flaw in an otherwise uniform slab of tissue, depicted in Figure 1. 

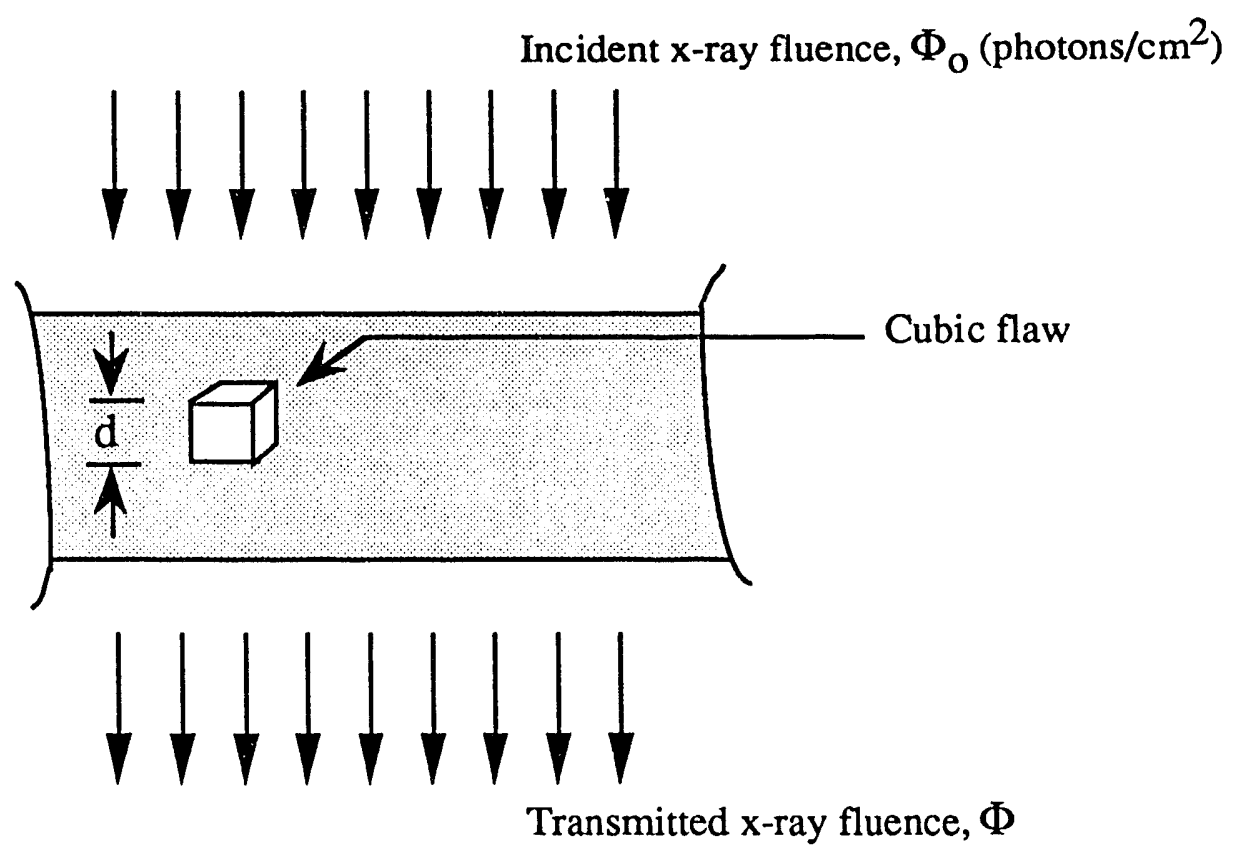

Figure 1. A simple model of the breast imaging process.

Simple analysis suggests that an optimum $x$-ray energy should exist for this situation. When the $\mathrm{x}$-ray energy is too high, the transmitted fluence approaches the incident fluence and sensitivity to variations in the breast vanishes. When $\mathrm{x}$-ray energy is too low, few are transmitted and the image becomes noisy. Since in this case, most of the energy is being absorbed as dose, increasing $\Phi_{0}$ is an unacceptable approach to reducing image noise.

It would be very useful to define a sensible optimization parameter, and to model mammography system performance as a function of $\mathrm{x}$-ray energy or spectrum. With a FISLIB mammography system, contrast in the displayed image is a key image attribute. With a digital image (even a digitized film image), contrast is easily adjusted provided that noise is small and dynamic range is adequate. It becomes one of many display parameters to be chosen to optimize presentation of the data. Our definition of system performance is the dose required to reliably detect a specified flaw.

\section{A Performance Model}

Consider the imaging situation previously described, only now include the effects of scatter. This is depicted in Figure 2. For this breast model, scatter can be treated as uniformly distributed at the detector plane (except for statistical fluctuations), since flaws of interest are too small in size and $x$-ray opacity to significantly perturb the scatter fluence. It is convenient to specify the scatter fluence as a ratio to the uncollided fluence. Let:

\footnotetext{
$\Phi_{1}=$ uncollided fluence in region 1

$\Phi_{2}=$ uncollided fluence in region 2

$\beta=$ scatter fluence $/ \Phi_{1}$
} 


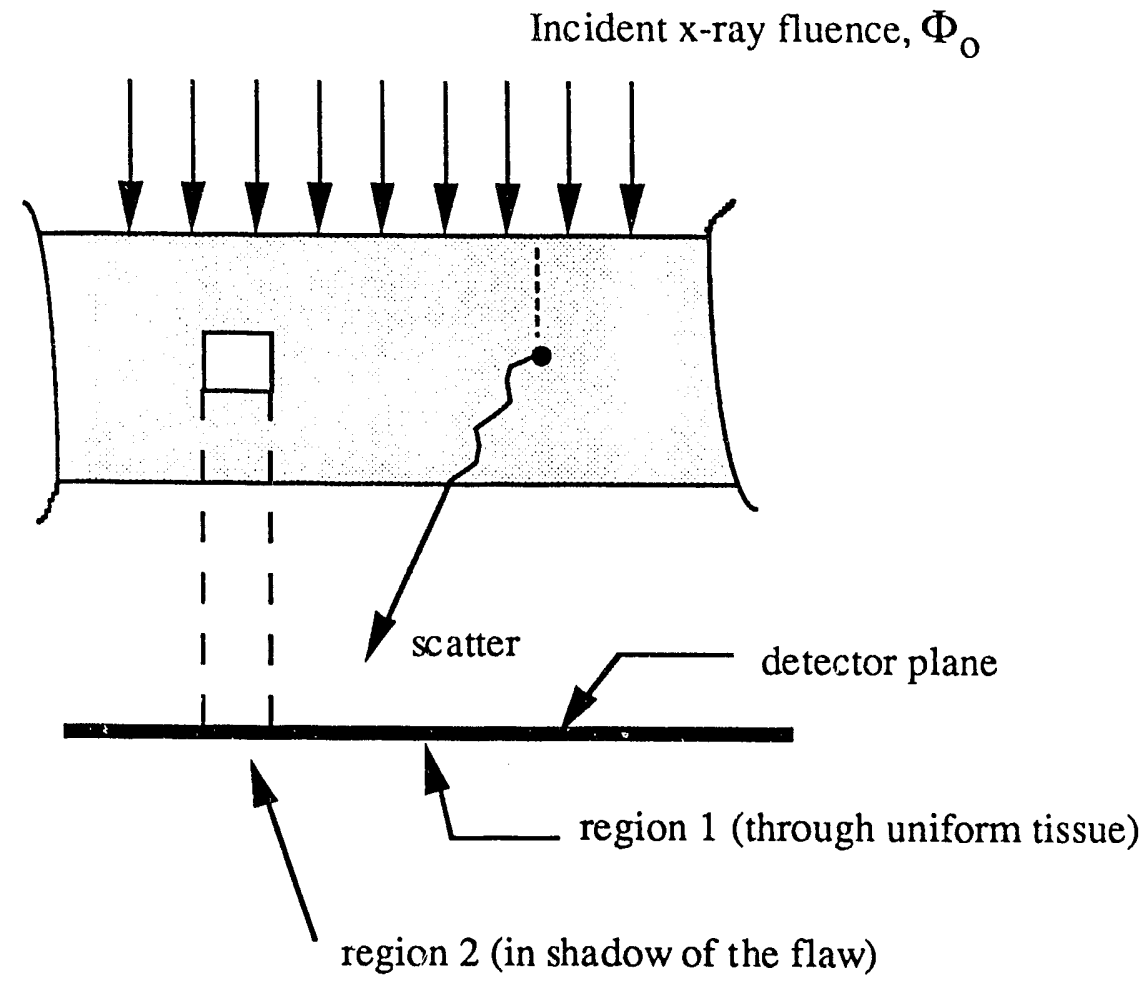

Figure 2. Breast imaging model with scatter

For now, consider the case of a perfect detector. That is, the detector counts all arriving photons equally without regard to energy or angle. This is the most interesting case to examine in order to understand what $x$-ray energy is optimum. Later, after we've attempted to design the perfect detector for the chosen spectrum, we can incorporate detector effects, both photon-energy and spatial resolution.

The signal, $S$, is given by the difference between the photon counts in the shadow of the flaw and the photon counts in a region of equal area away from the flaw.

$$
\left.S=(\text { photon counts })_{1}-\text { (photon counts }\right)_{2}
$$

Let:

$A=$ projected area of the defect
$d=$ defect dimension $=\sqrt{A}$

Then $S$ is given by:

$$
S=A\left[\Phi_{1}(1+\beta)-\left(\Phi_{2}+\beta \Phi_{1}\right)\right]
$$

or

$$
S=A\left[\Phi_{1}-\Phi_{2}\right]
$$

Equation 1

Equation 1 expresses mathematically the concept that scatter in digital mammography is profoundly different from scatter in a FISLIB system. Scatter has no effect upon the signal! If scatter were perfectly uniform we could simply remove it by subtraction. Of course scatter contains statistical fluctuations and therefore increases image noise. 
Let $\mathrm{n}$ denote the standard deviation of the components of the signal with the same subscript notation as used for fluences, so that:

$$
\begin{aligned}
& \mathrm{n}_{1}=\sqrt{\Phi_{1} \mathrm{~A}} \\
& \mathrm{n}_{2}=\sqrt{\Phi_{2} \mathrm{~A}} \\
& \mathrm{n}_{\beta}=\sqrt{\beta \Phi_{1} \mathrm{~A}}
\end{aligned}
$$

Then the standard deviation of the signal, $\mathrm{n}$, is:

$$
\mathrm{n}=\sqrt{\left(\sqrt{\mathrm{n}_{1}^{2}+\mathrm{n}_{\beta}^{2}}\right)^{2}+\left(\sqrt{\mathrm{n}_{2}^{2}+\mathrm{n}_{\beta}^{2}}\right)^{2}}
$$

or

$$
\mathrm{n}=\sqrt{\left[\Phi_{1}(1+2 \beta)+\Phi_{2}\right] \mathrm{A}}
$$

From Equations 1 and 2:

$$
\mathrm{S} / \mathrm{n}=\frac{\mathrm{A}\left(\Phi_{1}-\Phi_{2}\right)}{\sqrt{\mathrm{A}} \sqrt{\Phi_{1}(1+2 \beta)+\Phi_{2}}}
$$

We can express $S / n$ in terms of the incident $x$-ray fluence:

$$
\mathrm{s} / \mathrm{n}=\frac{\mathrm{d}\left(\eta_{1} \Phi_{0}-\eta_{2} \Phi_{0}\right)}{\sqrt{\eta_{1} \Phi_{0}(1+2 \beta)+\eta_{2} \Phi_{0}}}
$$

Where

$\eta_{1}=$ fractional transmission through perfect breast

$\eta_{2}=$ fractional transmission through flawed region flaw.

Solving equation 3 for $\Phi_{0}$ expresses the incicent fluence required to image a specified

$$
\Phi_{\mathrm{o}}=\frac{(\mathrm{S} / \mathrm{n})^{2}\left[(1+2 \beta) \eta_{1}+\eta_{2}\right]}{\mathrm{d}^{2}\left(\eta_{1}-\eta_{2}\right)^{2}}
$$


This is a remarkable result. We define the breast and the flaw. X-ray interaction cross sections set $\eta_{1}, \eta_{2}$ and $\beta$. Once we choose the required $S / n$, we can then directly compute $\Phi_{0}$ from equation 4. X-ray interaction cross sections determine dose for any given $\Phi_{0}$.

Determining $\mathbf{S} / \mathbf{n}$

Rose ${ }^{5}$ presents an elegant discussion of the visual process and of noisy images. It is often incorrectly assumed that all that is required for a signal to be detected above the noise is for the signal to be greater than the standard deviation of the noise $(S>n)$. A simple example shows that this is clearly insufficient if one considers the probability of false alarms occurring from statistical variations. Consider an $\mathrm{x}$-ray image made up of a million pixels. If we are searching for a single pixel whose value is less than the mean value by amount $n$, then we are faced with the problem that only 680,000 pixels are expected to lie within $\pm n$ of the mean (The probability of a value being within \pm one standard deviation of the mean is 0.68 ) and the probability of any given pixel value lying below our threshold is 0.16 . We will expect, therefore, to find about 160,000 "suspect" pixels. Clearly, 160,000 false positives per image is not acceptable, so a value of $S / n>1$ is required.

With the aid of a statistics reference, we can set reasonable values for $S / n$ based on what we feel is acceptable for the probability of random false positives. Interesting values fall between 4 and 6. For example when $S / n=4$, the probability of a random false occurrence is $3 \times 10^{-5}$. This value, $3 \times 10^{-5}$, is the area in one tail of a normal distribution beyond four standard deviations from the mean. This is about as large as is likely to prove useful. When $S / n=6$, the probability of a random false occurrence is $2 \times 10^{-9}$, small enough to satisfy the most demanding application.

For this interesting range of $4<S / n<6$, we have developed the expression

$$
\mathrm{S} / \mathrm{n}=1.84-0.478 \log _{10} \mathrm{P}
$$

where

$$
P=\text { the acceptable probability of a false event per pixel }
$$

Equation 5 is an easily-evaluated alternative to statistics tables. The degree of accuracy of the fit is shown in Figure 3. The four plotted points are taken from a standard statistics reference 6 . 


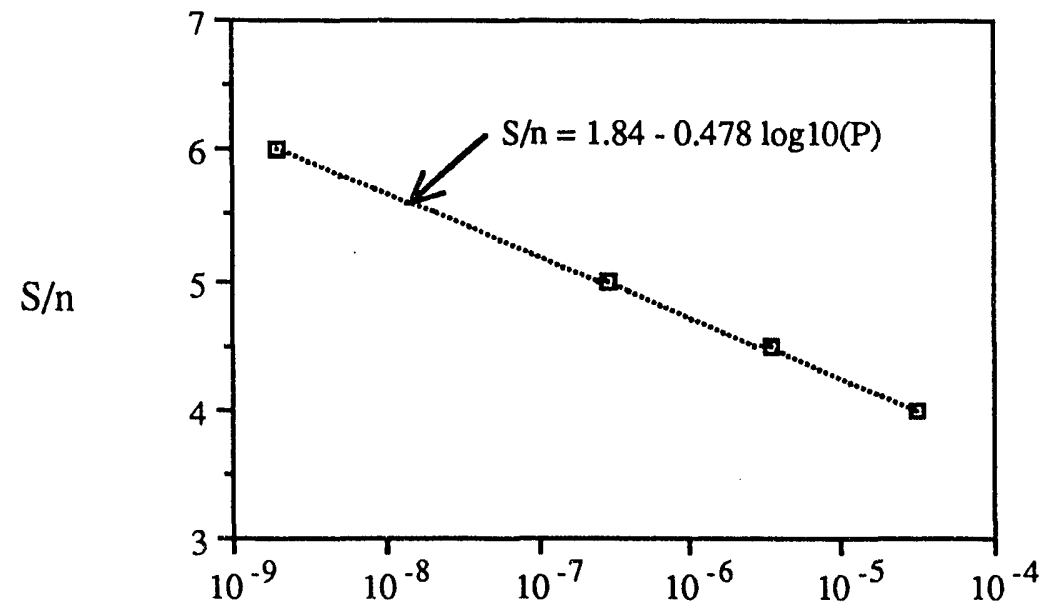

Per-pixel probability of a random false occurance

Figure 3. The value of $S / n$ required as a function of the acceptable probability of random false occurrences.

Let

$£=$ the acceptable rate of false positives per mammogram

$A_{b}=$ the area of the breast image

Then it is required that

$\mathrm{P}<\left(f \mathrm{~d}^{2}\right) / \mathrm{A}_{\mathrm{b}}$

and

$\mathrm{S} / \mathrm{n}>1.84-0.478 \log _{10}\left[\left(\mathfrak{f d}^{2}\right) / \mathrm{A}_{\mathrm{b}}\right] \quad$ Equation 6

For example, if we wish to find a $1 \mathrm{~mm}$ defect $(\mathrm{d}=0.1)$ and we want a region falsely appearing to be such a defect to occur only once every 10 images $(\mathfrak{f}=0.1)$, and if we are studying mammograms with $100 \mathrm{~cm}^{2}$ area $\left(A_{b}=100\right)$, evaluation of equation 6 indicates that $S / n$ must be greater than 4.2 .

Determining Dose, $\eta_{1}, \eta_{2}$ and $\beta$

We used the Monte Carlo code $\operatorname{TART}^{7}$ to compute dose, $\eta_{1}$, and $\beta$. TART is a flexible neutron and photon transport code. It utilizes the EPDL ${ }^{8}$ data library. This suite of codes and libraries have been under development for 30 years. The physics and cross sections for transport in the energy regime relevant to mammography are very well known. Our experience 9,10 is that the accuracy of these calculations exceeds all but the most carefully planned and executed experiments. It also permits options of calculating sources that are monochromatic and/or perfectly-collimated, and other difficult-to-attain experimental configurations.

We take our definition of tissue composition and density from ICRU44 ${ }^{11}$. These are reproduced in Table 1. 
Table 1

Tissue Composition (by mass) and Density

\begin{tabular}{llllllllll} 
Tissue & $\mathrm{H}$ & $\mathrm{C}$ & $\mathrm{N}$ & $\mathrm{O}$ & $\mathrm{Na}$ & $\mathrm{P}$ & $\mathrm{S}$ & $\mathrm{Cl}$ & $\rho\left(\mathrm{g} / \mathrm{cm}^{3}\right)$ \\
\hline Adipose & 11.4 & 59.8 & 0.7 & 27.8 & 0.1 & 0 & 0.1 & 0.1 & 0.950 \\
Mammary Gland & 10.6 & 33.2 & 3.0 & 52.7 & 0.1 & 0.1 & 0.2 & 0.1 & 1.020
\end{tabular}

The composition variation between adipose and gland gives rise to significant differences in $\mathrm{x}$-ray transport properties. "The adjective "dense" is often used to describe tissue of high x-ray opacity. This is especially true in mammography even though the difference in composition between various tissue types gives rise to variations in absorption that are far greater than the differences in density. For example, at $17.5 \mathrm{keV}$, if water is taken as having a mass attenuation coefficient of 1.0, adipose is 0.67 , and gland is 0.84 . These differences are far larger (and more important to transport) than the minor differences in density. The term "dense breasts" 12 has become part of the vocabulary. The composition of dense breasts is far more important to their $\mathrm{x}$-ray imaging qualities than is their density.

For our initial calculations, we modeled a breast of $50 \%$ adipose and $50 \%$ gland. In order to evaluate worst-case scattering, we calculated a right-cylindrical geometry with a radius of $10 \mathrm{~cm}$, in effect evaluating scatter at the center of a large breast. The source was directed along the axis of the cylinder. We did not include compression plates in the calculation. Our perfect detector was immediately adjacent to the breast at the exit side. This geometry is shown in Figure 4 . We treated all photons arriving at the detector plane within $35 \mu \mathrm{m}$ of the source axis as transmitted primary photons. All photons arriving at the detector plane at a position more than $35 \mu \mathrm{m}$ from the axis were tallied in a series of concentric ring tally zones. The total photon count outside of the central $35 \mu \mathrm{m}$ zone is divided by the primary photon count to yield $\beta$. The radial dependence of the scattered photon fluence is the point spread function for this configuration.

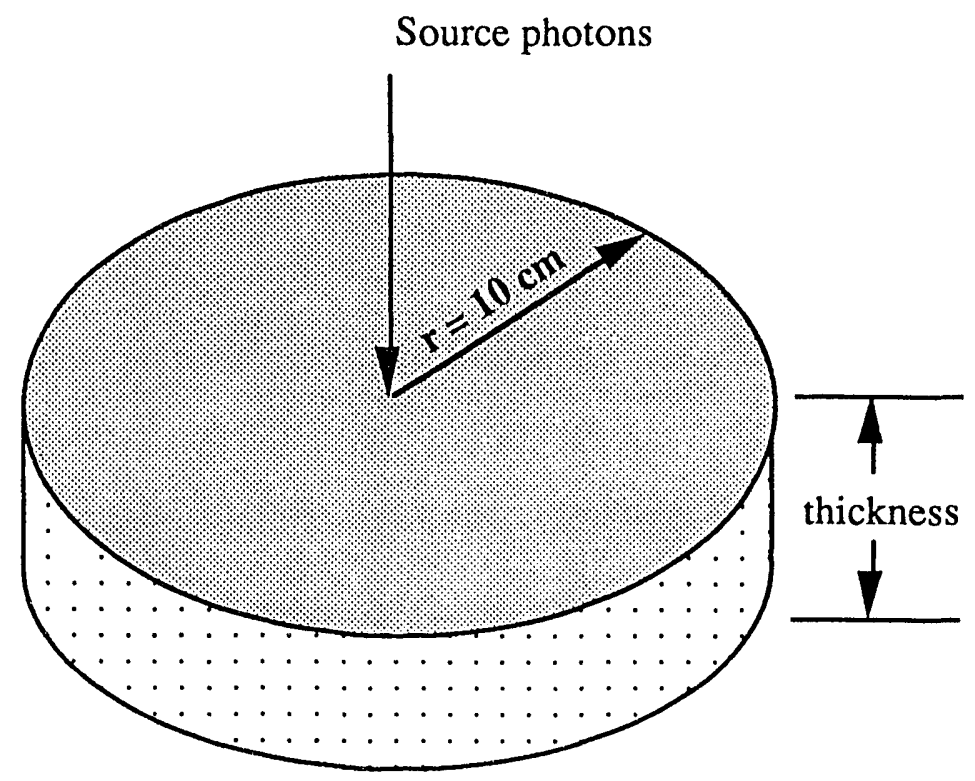

Figure 4. Geometry used for TART calculations. Detector plane is immediately adjacent to exit surface of breast.

We made 27 separate TART runs for breasts of 2,5 , and $8 \mathrm{~cm}$ thickness and for photons of $15,17.5,20,22.5,25,30,35,40$, and $50 \mathrm{keV}$. We chose the thickness to be representative of mean breast thickness \pm one standard deviation 13,14 . 
At 17.5-keV photon energy (representative of FiSLIB, Mo/Mo systems) dose is distributed non-uniformly through the breast thickness. Results for an $8 \mathrm{~cm}$ breast thickness are shown in Figure 5. The layers shown are each $0.5 \mathrm{~cm}$ in thickness. Else where in this paper wherever we cite a value for dose, it is the dose averaged over the entire breast thickness. Others define dose differently. Sometimes, a surface layer is excluded, or the dose at the midplane is cited. Clearly, very significant difference in dose can occur from alternative definitions. Also, tissue dose near the entrance surface can be five or more times the average dose.

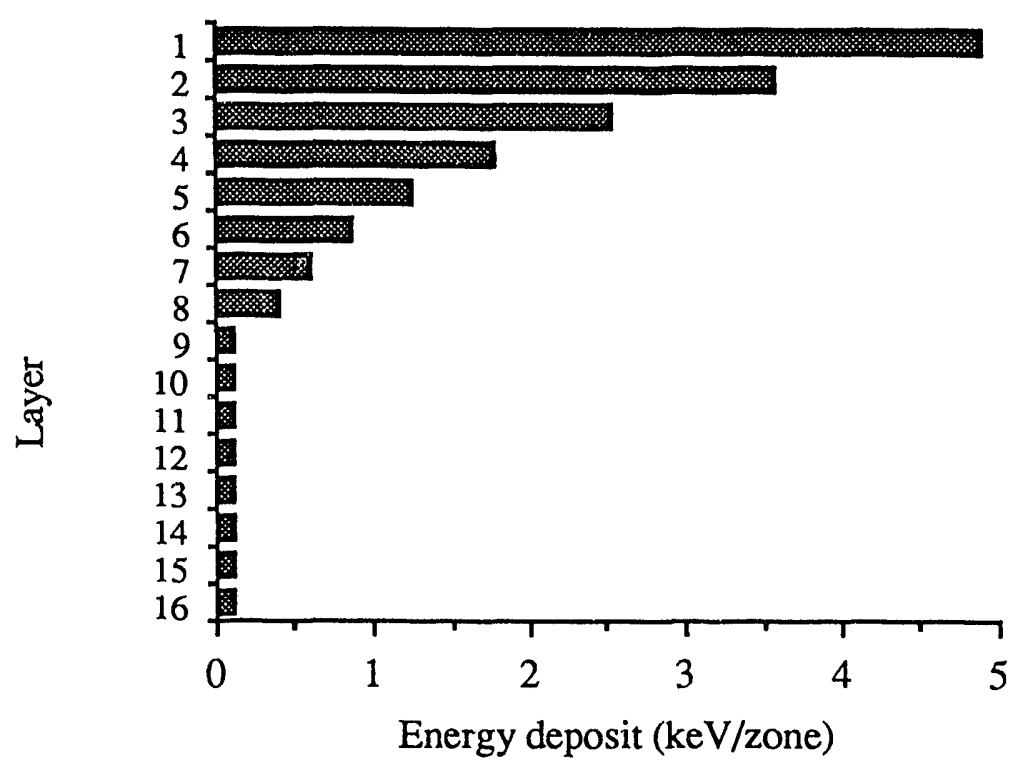

Figure 5. Distribution of energy deposition through the thickness of an $8 \mathrm{~cm}$ breast of 50/50 adipose/gland when irradiated with $17.5-\mathrm{keV}$ photons. Layers are $0.5 \mathrm{~cm}$ thick. Layers 9 through 16 were averaged in the calculation.

TART results for transmitted primary photons, dose, and scattered photons are presented in Figures 6, 7 and 8 and in Tables 2,3 and 4 . 


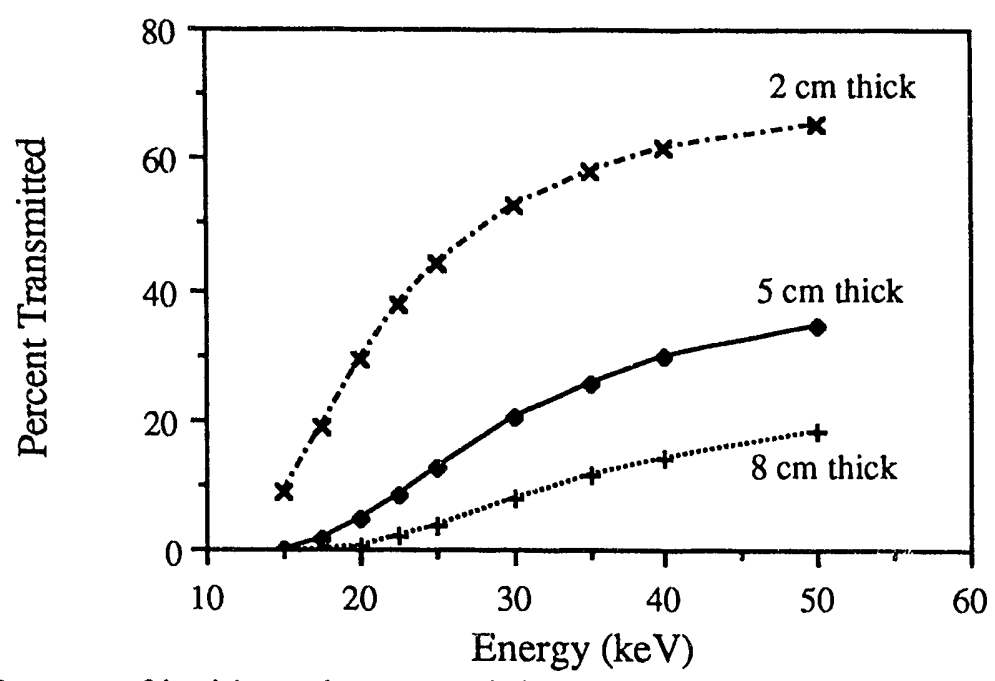

Figure 6. Percent of incident photons arriving at detector plane within $35 \mu \mathrm{m}$ of original trajectory.

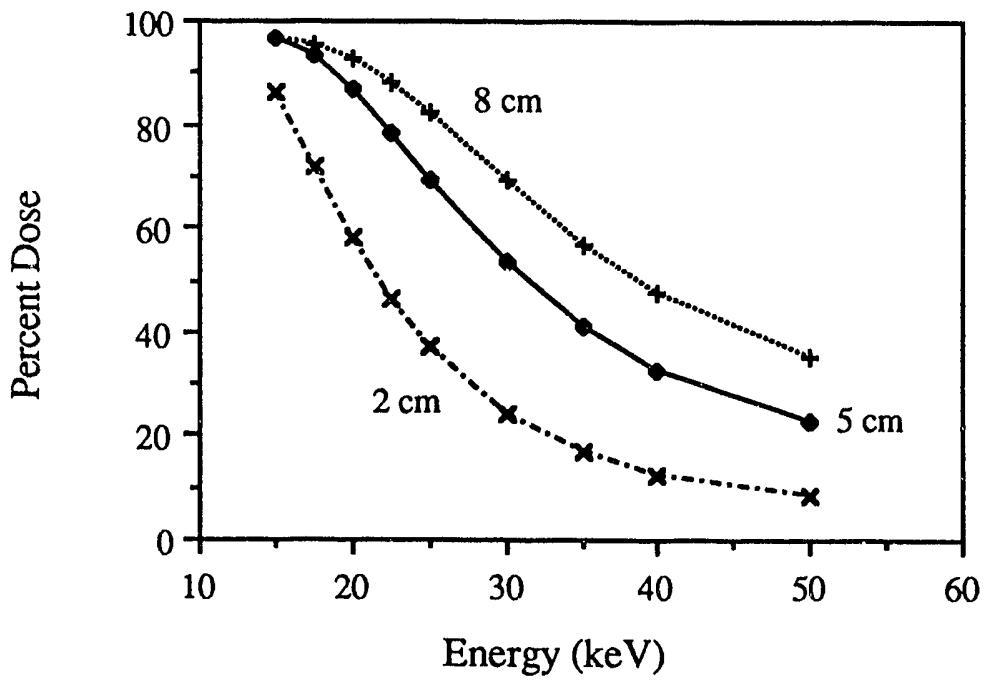

Figure 7. Percent of incident energy absorbed as dose. 


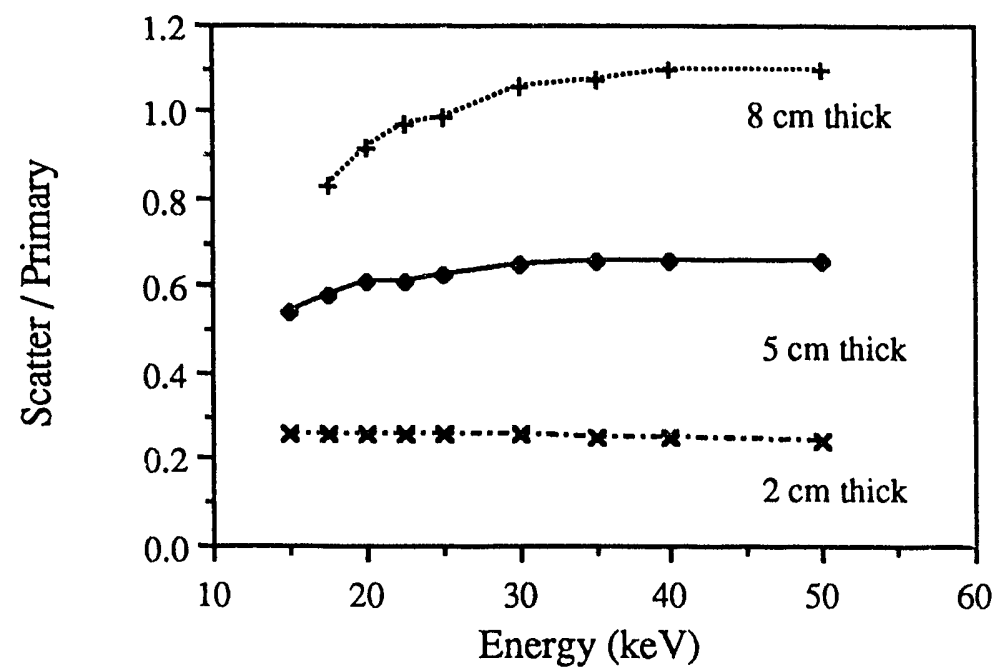

Figure 8. Ratio of scattered photons to primary photons, $\beta$.

Table 2

Percent of incident photons arriving at detector plane within $35 \mu \mathrm{m}$ of original trajectory.

\begin{tabular}{|r|r|r|r|}
\hline $\begin{array}{c}\text { Energy } \\
(\mathrm{keV})\end{array}$ & $2 \mathrm{~cm}$ & $\mathbf{5} \mathrm{cm}$ & $\mathbf{8} \mathbf{~ c m}$ \\
\hline \hline 15.0 & 8.758 & 0.233 & 0.005 \\
\hline 17.5 & 18.860 & 1.536 & 0.132 \\
\hline 20.0 & 29.060 & 4.500 & 0.702 \\
\hline 22.5 & 37.390 & 8.500 & 1.941 \\
\hline 25.0 & 43.820 & 12.640 & 3.673 \\
\hline 30.0 & 52.840 & 20.170 & 7.685 \\
\hline 35.0 & 58.200 & 25.710 & 11.350 \\
\hline 40.0 & 61.640 & 29.690 & 14.310 \\
\hline 50.0 & 65.580 & 34.680 & 18.320 \\
\hline
\end{tabular}


Table 3

Percent of incident energy absorbed as dose.

\begin{tabular}{|r|r|r|r|}
\hline $\begin{array}{c}\text { Energy } \\
(\mathbf{k e V})\end{array}$ & $2 \mathbf{c m}$ & $\mathbf{5} \mathbf{~ c m}$ & $\mathbf{8} \mathbf{~ c m}$ \\
\hline \hline 15.0 & 86.07 & 96.68 & 97.03 \\
\hline 17.5 & 72.09 & 93.19 & 95.36 \\
\hline 20.0 & 57.91 & 86.67 & 92.51 \\
\hline 22.5 & 46.17 & 78.37 & 88.05 \\
\hline 25.0 & 37.12 & 69.56 & 82.42 \\
\hline 30.0 & 24.47 & 53.35 & 69.24 \\
\hline 35.0 & 17.22 & 41.23 & 57.11 \\
\hline 40.0 & 12.74 & 32.62 & 47.46 \\
\hline 50.0 & 8.40 & 22.74 & 35.02 \\
\hline
\end{tabular}

Table 4

Ratio of scattered photons to primary photons.

\begin{tabular}{|r|r|r|r|}
\hline $\begin{array}{c}\text { Energy } \\
(\mathrm{keV})\end{array}$ & $2 \mathrm{~cm}$ & $\mathbf{5} \mathbf{c m}$ & $\mathbf{8} \mathbf{~ c m}$ \\
\hline 15.0 & 0.256 & 0.545 & 1.093 \\
\hline 17.5 & 0.258 & 0.583 & 0.834 \\
\hline 20.0 & 0.257 & 0.610 & 0.921 \\
\hline 22.5 & 0.258 & 0.615 & 0.970 \\
\hline 25.0 & 0.258 & 0.631 & 0.987 \\
\hline 30.0 & 0.256 & 0.652 & 1.059 \\
\hline 35.0 & 0.251 & 0.657 & 1.078 \\
\hline 40.0 & 0.248 & 0.660 & 1.096 \\
\hline 50.0 & 0.240 & 0.657 & 1.100 \\
\hline
\end{tabular}

We ran the TART calculations for a million source photons. This is sufficient to produce results with a statistical uncertainty of a few percent in every case except for transmission and scatter at $15 \mathrm{keV}$ and $8 \mathrm{~cm}$. We elected to omit these values on the plot of Figure 8 . We could have run this problem for more source photons, but it is not important since only $\sim 0.005 \%$ of the incident photons are transmitted to contribute to the image and $97 \%$ of the energy is absorbed as dose. Clearly not a very useful condition for optimal imaging.

We performed an energy balance for each TART calculation. In every case, the sum of: backscatter, radial leakage, energy entering the detector plane, and dose equals the incident photon energy to better than one part in $10^{4}$.

Even though we deliberately chose a large radius for these calculations, radial energy leakage is not entirely negligible in all cases, reaching $8 \%$ at $50-\mathrm{keV}$ photon energy and $8 \mathrm{~cm}$ thickness. This implies that our computed values for scatter could be influenced by leakage, and that more accurate modeling requires more accurate geometry including the chest wall and illuminated portions of the mammography unit. This will be the subject of future work.

That the contribution of scatter increases with increasing thickness is generally recognized 15,16 . Scatter does not significantly depend on $\mathrm{x}$-ray energy. It is generally reasoned 16 
that since Compton scattering accounts for an increasing proportion of the total interaction cross section as energy increases, the importance of scattering should also increase with increasing energy. However, the measurements of Barnes and Brezovich ${ }^{17}$, our Figure 8 and Table 4 show this reasoning to be flawed. Our results also compare well with the calculations of Firpo ${ }^{18}$, and with those of Dance and Day ${ }^{19}$.

Results

Results presented here are for monochromatic photons incident on a breast of 50/50 adipose/gland. Two different types of flaws are considered: a dense mass and a calcification. We also present the effect of calcification size on the dose required for detection. The detector is assumed to be a perfect photon detector.

\section{A $2 \mathrm{~mm}$ mass}

Consider the case of a $2 \mathrm{~mm}$ mass $(\mathrm{d}=0.2 \mathrm{~cm})$. We take mass to mean a cube of the same composition as the surrounding $50 / 50$ breast, but with a density that is 1.05 times the value of the 50/50 breast tissue. We set: $£=0.1$ and $A_{b}=100 \mathrm{~cm}^{2}$. The results are shown in Figure 9. The most striking aspect of this result is that photons below $20 \mathrm{keV}$ are simply inappropriate for this imaging task in breasts of 50/50 composition and greater than average thickness. Also, the dose required increases sharply with breast thickness. At $15 \mathrm{keV}$, the dose required to image this flaw in an $8 \mathrm{~cm}$ breast is one-thousand times the dose required in a $2 \mathrm{~cm}$ breast.

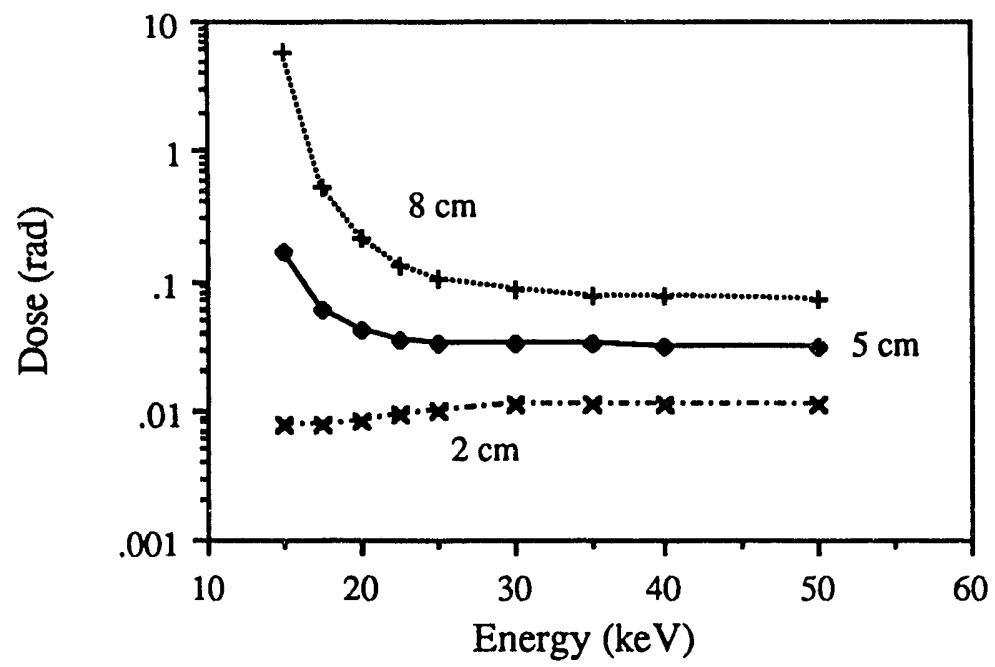

Figure 9. The dose required to image a $2 \mathrm{~mm}$ mass with $5 \%$ excess density in a breast of $50 / 50$ adipose/gland as a function of monochromatic photon energy. A perfect detector is assumed and all scatter is counted. ( $£=0.1, d=0.2$ and $\left.A_{b}=100 \mathrm{~cm}^{2}\right)$.

\section{A $100-\mu m$ calcification}

Next, consider the case of a $100-\mu \mathrm{m}$ calcification $(\mathrm{d}=0.01 \mathrm{~cm})$. We take the composition to be hydroxyapatite and the density to be $1.4 \mathrm{~g} / \mathrm{cm}^{3}$. Again we set: $£=0.1$ and $A_{b}=100 \mathrm{~cm}^{2}$. The results are shown in Figure 10. The variation in cross sections for tissue and hydroxyapatite cause minima to be present. 


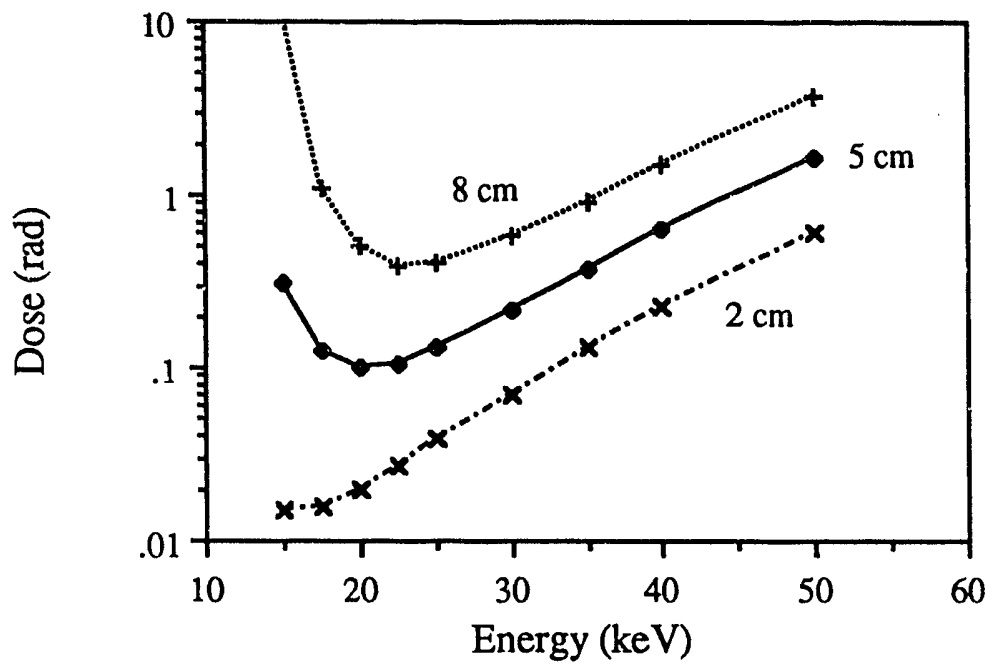

Figure 10. The dose required to image a $100-\mu \mathrm{m}$ calcification in a breast of $50 / 50$ adipose/gland as a function of monochromatic photon energy. A perfect detector is assumed and all scatter is counted. ( $f=0.1, d=0.01$ and $\left.A_{b}=100 \mathrm{~cm}^{2}\right)$.

\section{Effect of scatter suppression}

Suppression of scatter by grids or air gaps must be modelled in the Monte Carlo calculations to fully understand the potential benefits and optimal geometry, but our present model provides powerful insight. If one had a perfect grid, a grid fully transparent to primary photons and fully opaque to scattered photons, it would have the effect of setting $\beta=0$ in equation 4 . We have already shown that $\beta$ is nearly independent of photon energy and proportional to thickness. Examination of equation 4 then shows that the effect of perfect scatter suppression is to move the curves of Figures 9 and 10 lower and slightly closer together while leaving their shapes unaltered. It does not affect the choice of optimum energy.

Aspiring grid designers for digital mammography should see sobering news in equation 4. With a digital mammography system, scatter has no effect on signal; the only effect of scatter is to add noise. Since noise can always be reduced by acquiring more photons, the effects of scatter can always be fully negated by greater exposures. Since grids block some primary photons, they also require the use of greater exposures. The question of whether grids could prove useful boils down to whether they can improve $s / n$ at less cost in dose than simply using the additional dose to acquire an image with higher $\mathrm{s} / \mathrm{n}$.

We can approximately characterize the performance of a grid with two coefficients: $\varepsilon_{p}$ and $\varepsilon_{\mathrm{s}}$ where $\varepsilon_{\mathrm{p}}$ is the grid transmission for primary photons. Two effects are included in $\varepsilon_{\mathrm{s}}$. It equals the sum of the grid transmission for scattered photons and the scatter produced by the grid per incident primary photon. Let $\left(\Phi_{0}\right)_{\text {grid }}$ equal the incident fluence required to image a flaw when using a grid. With this notation we can modify equation 4 to include the first-order effect of using a grid. 


$$
\left(\Phi_{\mathrm{o}}\right)_{\text {grid }}=\frac{(\mathrm{S} / \mathrm{n})^{2}\left[\left(1+\frac{2 \varepsilon_{\mathrm{s}} \beta}{\varepsilon_{\mathrm{p}}}\right) \eta_{1}+\eta_{2}\right]}{\varepsilon_{\mathrm{p}} \mathrm{d}^{2}\left(\eta_{1}-\eta_{2}\right)^{2}}
$$

Equation 7

We can then set $\left(\Phi_{0}\right)_{\text {grid }}$ equal to $\Phi_{0}$ and solve for the set of $\varepsilon_{\mathrm{p}}$ and $\varepsilon_{\mathrm{s}}$ that represents break-even for a grid. This is the set of values where the loss of primary radiation is just balanced by the noise reduction from reduced scatter. Consider the case of a subtle defect $\left(\eta_{1} \approx \eta_{2}\right)$. Let the defect size, $d$ and the required $(S / n)$ be the same whether one uses a grid or doesn't use a grid. The break-even equation for the grid then reduces to:

$$
\varepsilon_{\mathrm{s}}=\left[(1+\beta) \varepsilon_{\mathrm{p}}{ }^{2}-\varepsilon_{\mathrm{p}}\right] / \beta
$$

Equation 8

We showed earlier that at the exit surface, near the center of a large-area breast , $\beta=0.28$, 0.6 and 1.0 for thin, average and thick breasts. Equation 8 for these conditions is presented in Figure 11. To be useful, a grid must be positioned below and to the right of the break-even line. Any grid whose coefficients place it to the left and above the line will cause a net loss in $(S / n)$ at constant dose. Scatter can also be reduced by use of a slot or fan beam and by utilizing a gap between breast and detector. Unless it can be shown that the spatial dependence of scatter is important to image interpretation, the performance of grids in common use ${ }^{20}$ is unlikely to be useful for digital mammography.

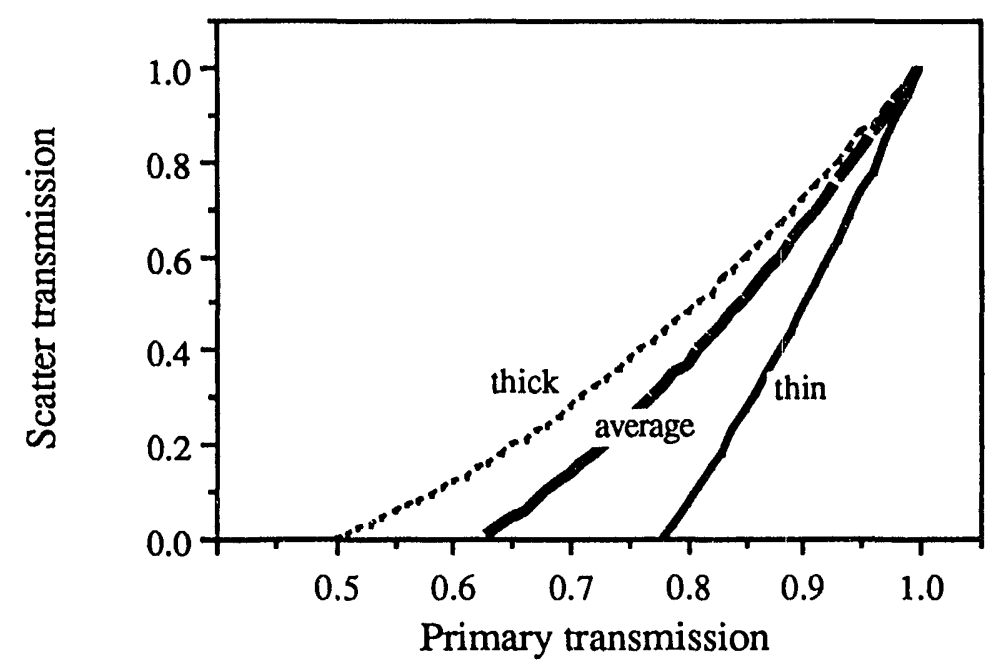

Figure 11. Grid performance break even line for digital mammography with a detector in contact with the exit surface of large area breasts of 50/50 composition.

\section{Effect of varying $£$ and $A_{b}$}

The effect of varying $£$ and $A_{b}$ is small. Their influence is through the log term of equation 6 and is independent of energy and thickness. Reducing $£$ a factor of 10 to 0.01 , changes S/n from 4.2 to 4.7 and increases the required dose by only $25 \%$. 


\section{Effect of varying flaw size}

The effect of varying the flaw size is substantial. Varying flaw size does not significantly change the shape of the dose vs. photon energy curves, and therefore the choice of optimal photon energy, but changing flaw size has a huge effect on the dose required to image a flaw. This is illustrated in Figure 12 where we present the dose required to image a calcification in an $8 \mathrm{~cm}$ breast as a function of calcification size for photons at $17.5 \mathrm{keV}$ and $22.5 \mathrm{keV}$. The $22.5-\mathrm{keV}$ photons are about a factor of 3 more efficient for this imaging task, but even this large factor results in only modest extension of the lower limit of detectability at constant dose.

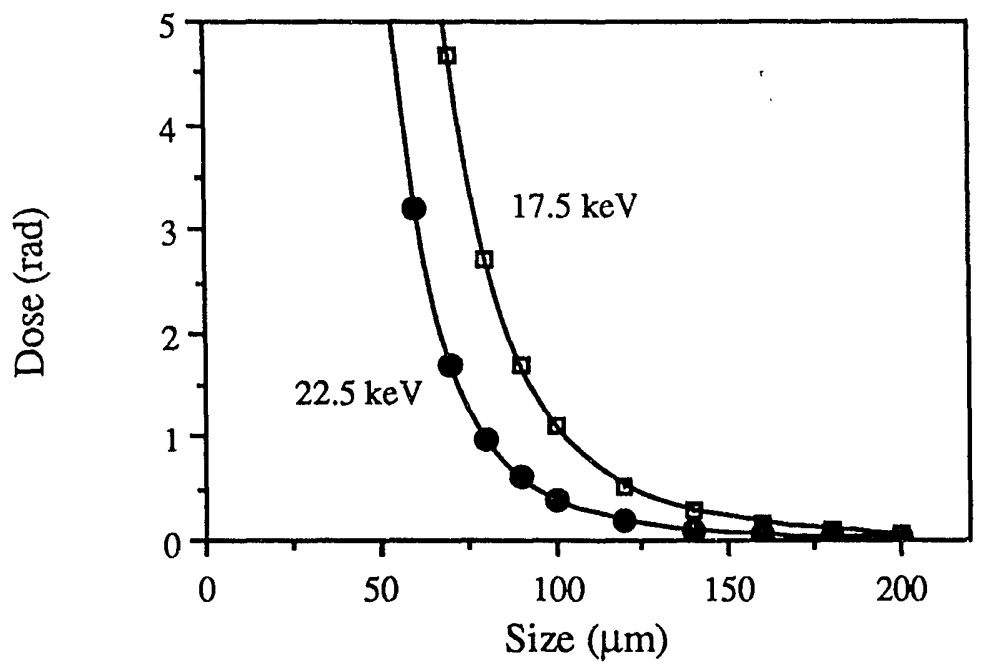

Figure 12. The dose required to image a calcification in an $8 \mathrm{~cm}$ breast of 50/50 adipose/gland as a function of calcification dimension for two photon energies. A perfect detector is assumed and all scatter is counted. ( $\left(\mathfrak{=}=0.1\right.$ and $\left.\mathrm{A}_{b}=100 \mathrm{~cm}^{2}\right)$.

\section{Source requirements}

The results of Figure 9 and 10 are expressed in terms of dose. These could also be expressed in terms of the required incident fluence. Figure 13 is the fluence required for the more demanding of the imaging tasks we explored - the $100-\mu \mathrm{m}$ calcification in an $8 \mathrm{~cm}$ thick breast of $50 / 50$ adipose/gland. The number of $22.5-$ or $25-\mathrm{keV}$ photons required is about one-third of the requirements if the photon energy is $17.5 \mathrm{keV}$. 


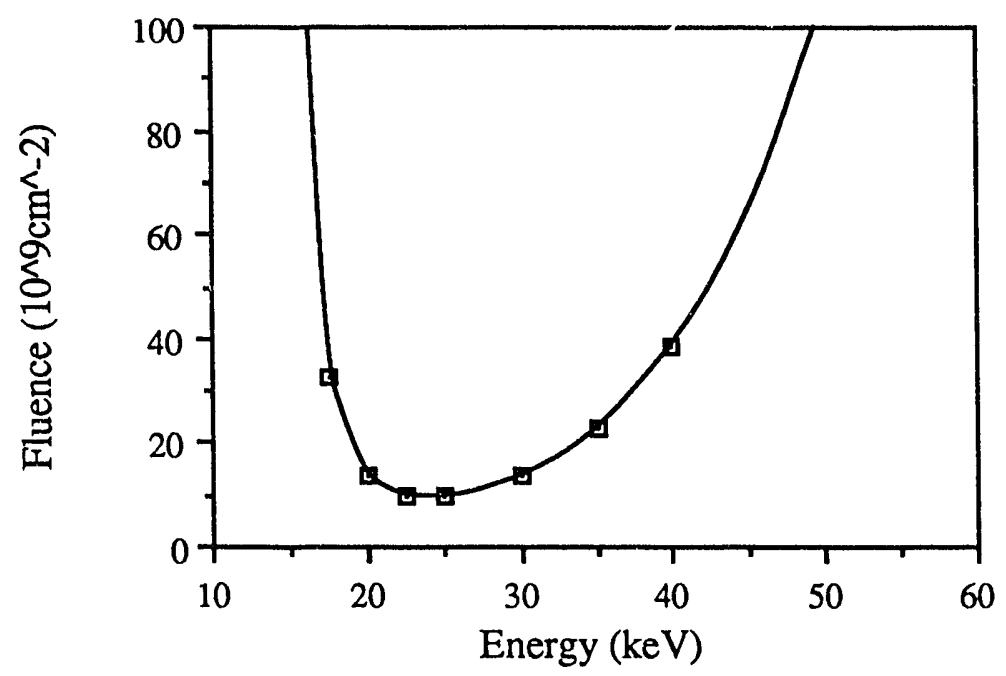

Figure 13. The fluence required to image a $100 \mu \mathrm{m}$ calcification in an $8 \mathrm{~cm}$ breast of $50 / 50$ adipose/gland as a function of monochromatic photon energy. A perfect detector is assumed and all scatter is counted. ( $\left(\mathfrak{=}=0.1\right.$ and $\left.A_{b}=100 \mathrm{~cm}^{2}\right)$.

\section{Population dose}

The dose required for breast imaging increases rapidly with breast thickness. The data of Figures 9 and 10 are well represented by exponentials of the form

$$
\text { Dose }=a \mathrm{e}^{\mathrm{bt}}
$$

Where $t$ is breast thickness and $a \& b$ are fitting parameters. If we represent the dose vs. thickness as a fitted exponential and treat the population as Gaussian with a mean breast thickness of $5.0 \mathrm{~cm}$, a standard deviation of $1.5 \mathrm{~cm}$, and composition of 50/50 adipose/gland, we can then numerically integrate over the population for various situations. The results of integration for imaging a $100-\mu \mathrm{m}$ calcification (the imaging task shown in Figure 10) using photons of energy $17.5 \mathrm{keV}$ and $22.5 \mathrm{keV}$ are presented in Figure 14. 


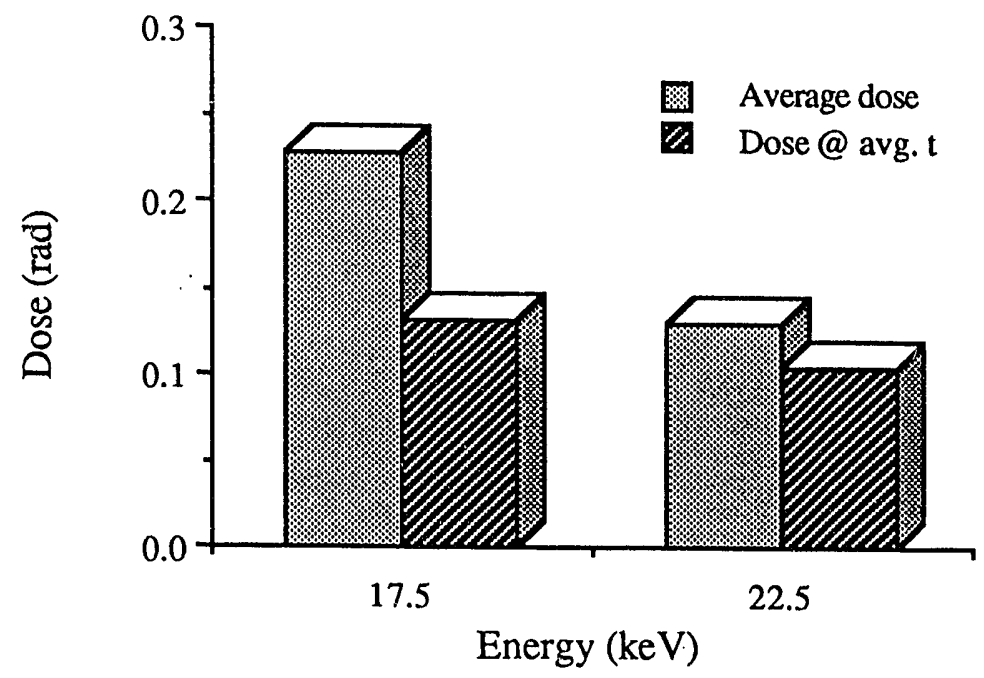

Figure 14. The average population dose and the dose to the breast of average thickness that is required to image a $100-\mu \mathrm{m}$ calcification in a breast of 50/50 adipose/gland for two photon energies. A perfect detector is assumed and all scatter is counted. $(\mathfrak{f}=0.1$ and $A_{b}=100 \mathrm{~cm}^{2}$ ).

The greater penetrating power of higher-energy photons reduces the dose disparity between large and small-breasted women. One illustration of this is shown in Figure 15 which depicts the ratio of the dose delivered to the thickest $5 \%$ of the population to the dose delivered to the thinnest $5 \%$ of the population.

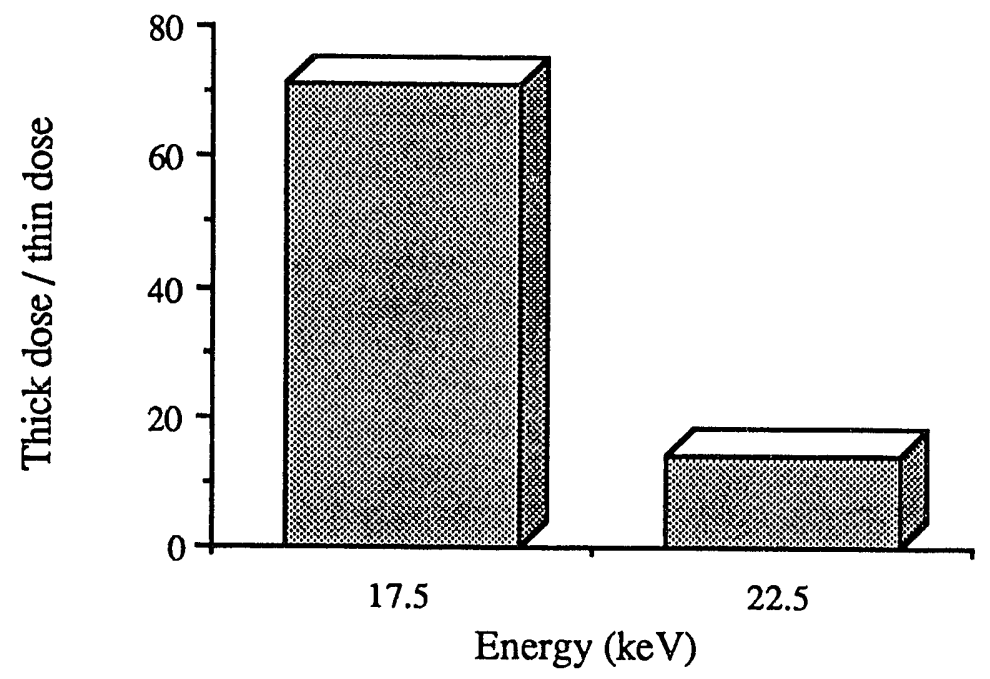

Figure 15. A measure of the dose disparity between thick and thin breasts for two photon energies. Shown are the doses required to image a $100-\mu \mathrm{m}$ calcification in the thickest $5 \%$ of the population divided by the dose required for the same imaging task in the thinnest $5 \%$ of the population. Breasts of $50 / 50$ adipose/gland, $5 \mathrm{~cm}$ mean breast thickness, $1.5 \mathrm{~cm}$ thickness standard deviation, and a perfect detector is assumed. All scatter is counted. ( $£=0.1$ and $\left.A_{b}=100 \mathrm{~cm}^{2}\right)$. 
Discussion

Although we have not yet completed the analysis, including the effect of variable breast composition will cause the dose distribution throughout the population to become even more skewe $d$ toward large, dense breasts. That is, women with large dense breasts will account for an even iarger proportion of the total dose than the results presented here. Even without including this effect, applied across the population, $22.5-\mathrm{keV}$ photons are superior in every respect to $17.5-\mathrm{keV}$ photons.

Risk from mammography is expected to be proportional to the population dose. Therefore, average dose is the relevant measure of risk. Note from Figure 14 how poorly the dose to the breast of average thickness correlates with average dose. The dose to a breast of average thickness is useless as a measure of risk to the population.

Two approaches to an appropriate spectrum for digital mammography will be investigated in future work: W-anode and Ag- (or Rh-) anode. Spectral tailoring is possible with W-anode tubes, by adjusting the applied voltage and filtration. Since we have shown that the source requirements are relaxed by about a factor of three by increasing photon energy from 17.5 to 22.5 $\mathrm{keV}$, perhaps the lower output of $\mathrm{W}$-anode tubes will be acceptable.

The second approach to a more appropriate spectrum is to use an anode material with $\mathrm{K}$-characteristic lines at the desired energy. Both $\mathrm{Ag}$ and $\mathrm{Rh}$ look promising. We have performed $2-\mathrm{D}$ thermal analysis ${ }^{21}$ of a rotating silver anode with TOPAZ2D 22 . The results suggest that this approach may be possible. Rh is of course a more refractory material than Ag. A Rh-anode tube is clearly feasible, but is unlikely to match the spectral performance of $\mathrm{Ag}$.

\section{Conclusions}

This study shows that a spectrum rich in $22-$ to $25-\mathrm{keV}$ photons is required for digital mammography. X-ray tubes with Ag- or $\mathrm{Rh}$-anodes are promising. To gain the maximum advantage will require design of detector systems capable of high quantum efficiency and spatial resolution at these energies.

We acknowledge B. J. Schumacher for key contributions to this work. 
References

1. Mammography - A User's Guide, NCRP Report No. 85, National Council on Radiation Protection (Bethesda MD/1986).

2. Medical Electronics \& Equipment News, Vol. 34, No. 4, Reilly Publishing Co. (Park Ridge IL/1991).

3. R. J. Jennings and T. R. Fewell, Filters - Photon Energy Control and Patient Exposure, in Reduced Dose Mammography, Eds. Logan and Muntz. Masson Publishing (New York NY/1979).

4. D. R. Dance and G. J. Day, Simulation of Mammography by Monte Carlo Calculation The Dependence of Radiation Dose, Scatter and Noise on Photon Energy, In: Patient Exposure to Radiation in Medical X-ray Diagnosis, pp 227-243. Eds. Drexler, Eriskat, and Schibilla, CEC (Brussels/1981).

5. A. Rose, Vision: Human and Electronic, Plenum Press (New York NY/1973).

6. Lyman Ott, An Introduction to Statistical Methods and Data Analysis, Third Edition, (PWS-Kent Publishing Co., Boston MA/1988).

7. John R. Kimlinger, Nancy L. Monson, and Ernest F. Plechaty, TART and ALICE Input Manual, UCID 17026 Rev.3, Lawrence Livermore National Laboratory (Livermore CA/1990).

8. D. E. Cullen M. H. Chen, J. H. Hubbell, S. T. Perkins, E. F. Plechaty, J. A. Rathkopt, and J. H. Scofield, Tables and Graphs of Photon-Interaction Cross Sections from 10 eV to $100 \mathrm{GeV}$ Derived from the LLNL Evaluated Photon Data Library (EFDL), UCRL-504000, Vol. 6, Rev.4, Lawrence Livermore National Laboratory (Livermore CA/1989).

9. Daniel L. Lewis, Clinton M. Logan and Mark R. Gabel, Continuum X-ray Gauging of Multiple-Element Materials, Spectroscopy, Vol.7, No.3, Aster Publishing Co. (Eugene OR/1992).

10. J. M. Hernandez, C. M. Logan, P. B. Mohr and D. L. Weirup, Quantitative Film Radiography, International Advances in Nondestructive Testing, Vol.17, Gordon and Breach (1992).

11. Tissue Substitutes in Radiation Dosimetry and Measurement, ICRU Report 44, International Commission on Radiation Units and Measurements (Bethesda MD/1989).

12. Carolyn Kimmee-Smith, National Cancer Institute Breast Imaging Workshop, September 1991 - Meeting News, AJR, Vol. 158, p. 268 (February 1992).

13. Daniel C. Sullivan, Craig A. Beam, Suzanne M. Goodman, and Donald L. Watt, Measurement of Force Applied during Mammography, Radiology, Vol. 181, No. 2, p.355 (November 1991).

14. Clint Logan and Robert Boroff, Range of Incident Radiation Intensity Required for Various Breast Thicknesses, in preparation.

15. S. Webb (editor), The Physics of Medical Imaging, Adam Hilger (Bristol, England/1988).

16. Albert Macoviski, Medical Imaging Systems, Prentice Hall (Englewood Cliffs NJ/1983). 
17. G. T. Barnes and I. A. Brezovich, "The Intensity of Scattered Radiation in Mammography", Radiology, Vol. 126, p. 243-247 (1978).

18. M. A. Firpo, Photon Transport in Mammography: Monte Carlo Simulation, Masters Thesis, San Diego State Universtiy (San Diego CA/1989).

19. David R. Dance and Graham J. Day, The Computation of Scatter in Mammography by Monte Carlo Methods, Phys. Med. Biol., Vol. 29, No. 3, p. 237 (1984).

20. H-P. Chan, P. F. Frank, K. Doi, I. Iida, and Y. Higashida, Ultra-High-Strip-Density Radiographic Grids: A new Antiscatter Technique for Mammography, Radiology, Vol. 154 , p. 807-815 (1985).

21 E. H. Moor, A Thermal Comparison of Silver and Molybdenum as E-Beam Targets in $X$-ray Tubes, LLNL report END92-027 (1992).

22. A. B. Shapiro and A. L. Edwards, The TOPAZ2D Heat Transfer Code Users Manual and Thermal Property Data Base, LLNL Report UCRL-ID-104558 (1990). 

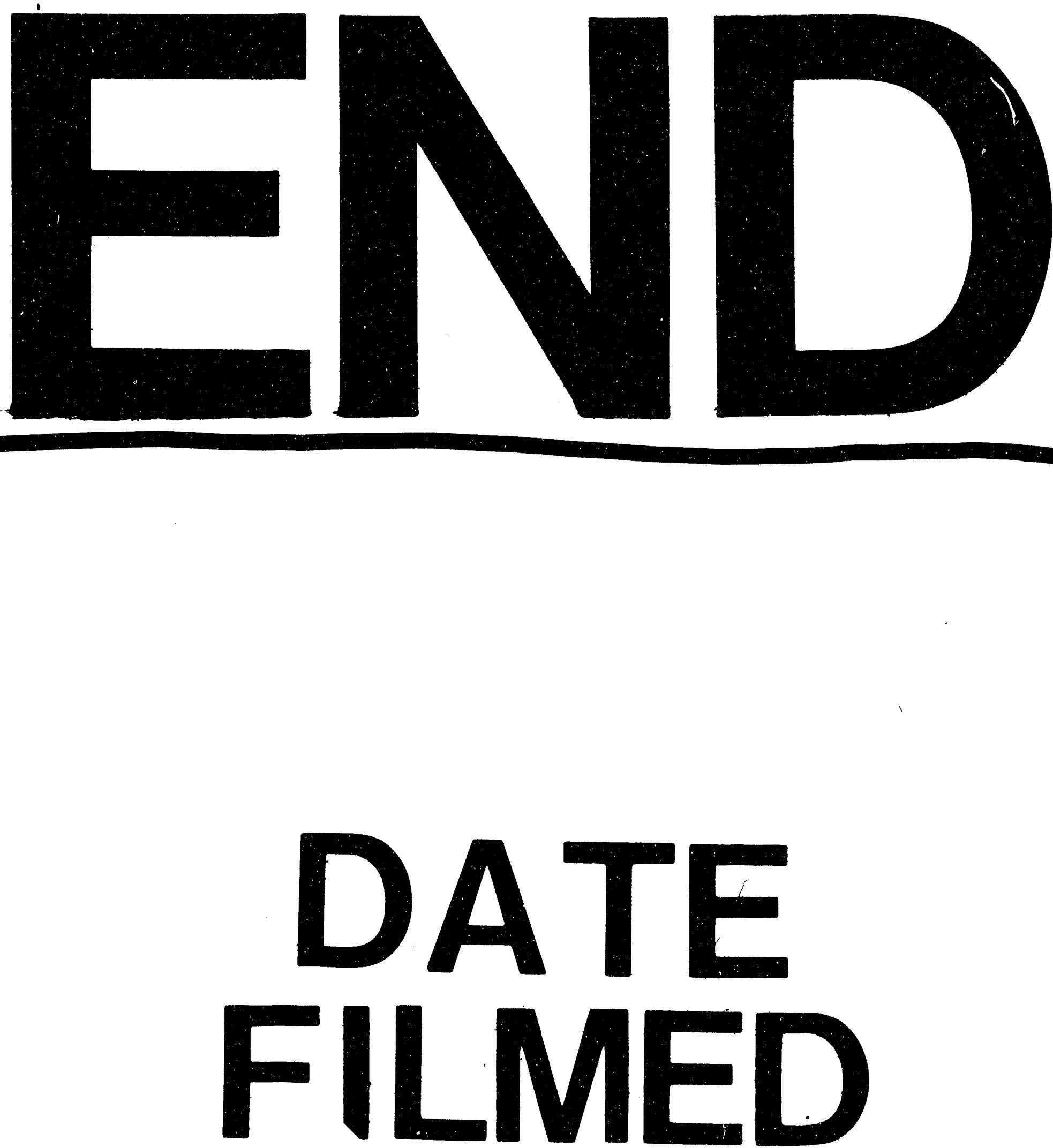

9
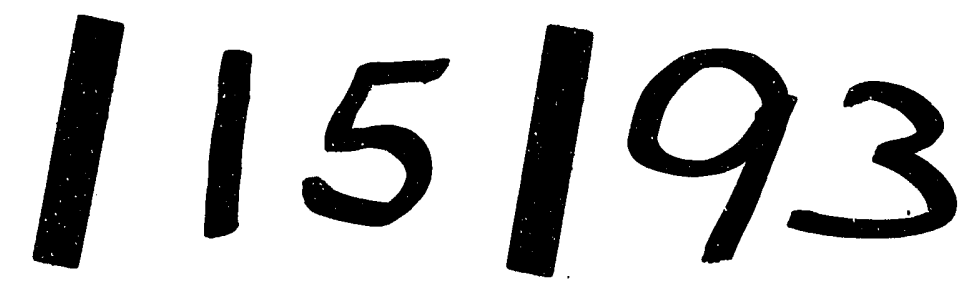
